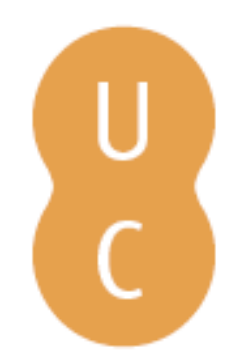

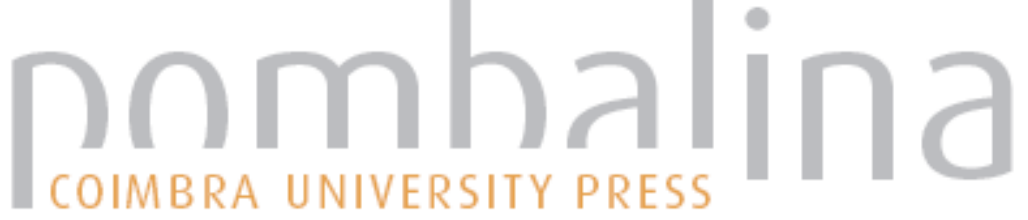

\section{O dom como fundamento de uma cultura democrática e associativa}

\author{
Autor(es): Martins, Paulo Henrique \\ Publicado por: Imprensa da Universidade de Coimbra \\ URL \\ persistente: \\ URI:http://hdl.handle.net/10316.2/31317 \\ DOI: \\ DOI:http://dx.doi.org/10.14195/978-989-26-0222-6_1
}

Accessed : $\quad$ 26-Apr-2023 09:32:10

A navegação consulta e descarregamento dos títulos inseridos nas Bibliotecas Digitais UC Digitalis, UC Pombalina e UC Impactum, pressupõem a aceitação plena e sem reservas dos Termos e Condições de Uso destas Bibliotecas Digitais, disponíveis em https://digitalis.uc.pt/pt-pt/termos.

Conforme exposto nos referidos Termos e Condições de Uso, o descarregamento de títulos de acesso restrito requer uma licença válida de autorização devendo o utilizador aceder ao(s) documento(s) a partir de um endereço de IP da instituição detentora da supramencionada licença.

Ao utilizador é apenas permitido o descarregamento para uso pessoal, pelo que o emprego do(s) título(s) descarregado(s) para outro fim, designadamente comercial, carece de autorização do respetivo autor ou editor da obra.

Na medida em que todas as obras da UC Digitalis se encontram protegidas pelo Código do Direito de Autor e Direitos Conexos e demais legislação aplicável, toda a cópia, parcial ou total, deste documento, nos casos em que é legalmente admitida, deverá conter ou fazer-se acompanhar por este aviso. 
Sílvia Portugal

Paulo Henrique Martins

Organização

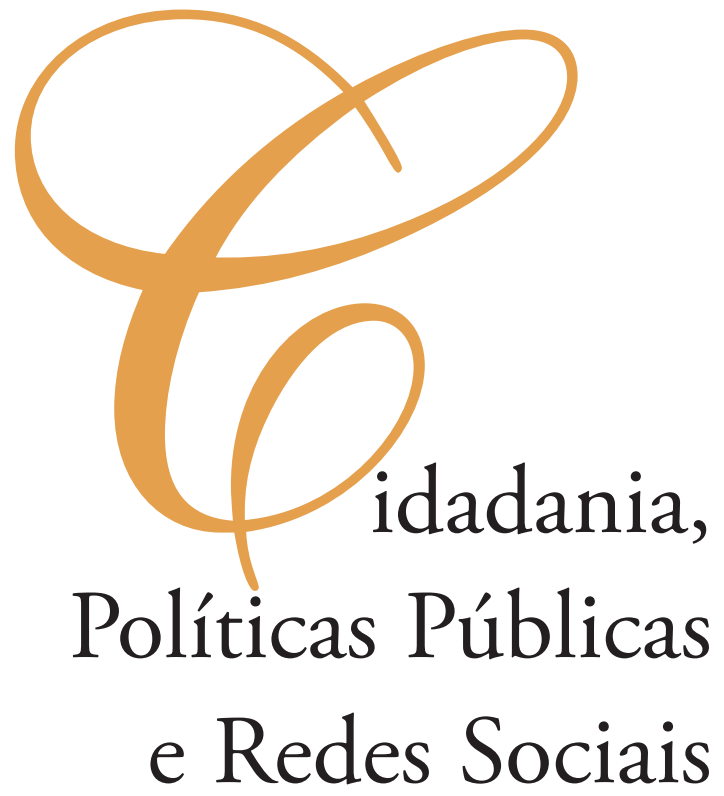


Paulo Henrique Martins

\section{O DOM COMO FUNDAMENTO \\ DE UMA CULTURA DEMOCRÁTICA E ASSOCIATIVA}

\section{Introduçáa $^{1}$}

Neste capítulo propomos que as atuais dificuldades de emancipação de um pensamento democrático de caráter participativo, que são observadas em diferentes contextos, revelam apenas em parte as resistências do pensamento hegemônico utilitarista e mercantilista à adoção de idéias e iniciativas voltadas para uma revalorização da função regulatória do direito entre a faticidade e a validade, como vemos em Habermas (2003). Ou as resistências à adoção de um direito procedimental que permita a transformação do Estado-providência em um Estado-serviço, refazendo a relaçáo sociedade-indivíduo e promovendo melhor redistribuição das riquezas coletivas, inclusão social e maior participação dos atores sociais, como encontramos em Rosanvallon (1995).

No nosso entendimento, tais dificuldades expressam igualmente um outro aspecto que não tem a ver diretamente com a influência do utilitarismo prático e normativo sobre as instituiçóes sociais, mas com a compreensão insuficiente a respeito do modo como o simbolismo aparece no surgimento de alianças e pactos responsáveis pelo trabalho de socialização e formação do caráter e, também, na organização de solidariedades culturais e políticas. Ou seja, apesar do impacto considerável que a descoberta do simbolismo teve classicamente na sociologia, na filosofia e na antropologia, pelas mãos de autores como Mauss (2003), Cassirer (2004) e Lévi-Strauss (2003), não houve ainda o aproveitamento adequado dessas contribuiçóes em termos de repensar as relaçóes entre simbolismo, poder político e democracia. Talvez pelo fato de que os fundamentos simbólicos da vida associativa, dos elementos significativos da consciência coletiva, não sejam visíveis facilmente a partir de uma lógica instrumental, as ciências sociais conhecem dificuldades de incorporar a "fenomenologia da percepção" como base conceitual de suas narrativas críticas.

Sem o entendimento sócio-antropológico adequado a respeito dos fundamentos imaginários e normativos da associação primária entre seres humanos, a ação pública se molda fatalmente em procedimentos administrativos que limitam o horizonte do controle social à aplicação fortuita e pragmática de mecanismos de regulamentação da prática social e de

${ }^{1}$ Faço um agradecimento especial a Maria Cristina Reigadas, cujos comentários foram importantes para melhor sistematizarmos nossa defesa de uma democracia participativa que, sem negligenciar o procedimentalismo, valorize sobretudo o simbolismo, a associação e o dom. 
instrumentalização das instituiçóes que, muitas vezes, apenas ampliam os fenômenos de anomia social. Assim, pela dificuldade de entronizar os fundamentos imaginários e simbólicos da ação humana, as intervenções racionais e planejadas sobre o social tornam-se frequentemente paliativas, superficiais e insuficientes para deter os processos de desorganização, tanto do sistema - a esfera pública e estatal - como do mundo da vida - as práticas do cotidiano -, ao mesmo tempo que terminam favorecendo a dominação da esfera pública pelo sistema mercantil. Nossa hipótese é, pois, que a articulação desta dimensão sócio-antropológica do "mundo da vida", a do simbolismo, com novas açóes públicas que favoreçam o espírito associativo e a esfera pública democrática, é uma tarefa central na discussão sobre democracia, hoje.

Enquanto as atençôes do debate acadêmico voltam-se prioritariamente para o estudo dos procedimentos da participação democrática, dando ênfase no consenso, como faz Habermas, ou no dissenso, como o faz Luhmann (Neves, 2001: 142-145), perde-se de vista que a esfera pública apenas aparece como "mundo comum", "que é comum a todos nós e diferente do lugar que nos cabe dentro dele" (Arendt, 2003: 62), devido a tal esfera se sustentar num magma de significaçóes compartilhadas no mundo vivido e percebido.

Ou seja, embora os estudos das racionalidades procedimentais e sistêmicas sejam importantes para entender a democracia deliberativa, devemos entender que a ênfase excessiva sobre tais racionalidades suprime parte da energia intelectual necessária para se descrever e se explicar o fato de que o fenômeno da participaçáo ocorre primeiramente no plano das significaçóes compartilhadas no plano intersubjetivo, ou do que Charles Taylor define como ontologias morais, que articulam as representaçóes sobre a dignidade, sobre o viver junto e sobre o respeito peculiar aos direitos (Taylor, 2005: 25). Apenas em um segundo momento, depois que se estabelecem alianças e mecanismos de reciprocidade entre as subjetividades presentes no contexto da vida, pode a dádiva emergir como valor moral revelador da práxis política, das regras de solidariedade e dos procedimentos jurídicos e administrativos que asseguram a validade da justiça e do direito no plano formal.

Neste texto, defendemos, em suma, a hipótese de que a ausência de um aprofundamento dos fundamentos subjetivos dos processos de constituição de alianças e solidariedades repercute negativamente na adoção de iniciativas coletivas e cívicas, em geral, e de políticas estatais, em particular, que possam fortalecer a estruturação de uma esfera pública democrática e participativa, ancorada num direito comunitário e de propriedade mais igualitário, a médio e longo prazo. Tal ausência de aprofundamento desta compreensão do simbolismo da ação social inibe, por conseguinte, a tarefa de reorganizar a representação política pela ótica de uma responsabilidade fundada na permanência, baseada em uma transcendência temporal que extrapole a duração de vida dos mortais e integre uma compreensão ética menos imediata e mais alongada da vida (Arendt, 2003: 64; Jonas, 1997: 14). Pois, na medida em que a ação política, em geral, e a ação estatal, em particular, se limitam a uma "metafísica da presença" que condiciona o campo dos movimentos político-estratégicos à objetividade social imediata, perde-se de vista a importância da dualidade, do antagonismo e do conflito na produçáo do mundo da vida (Mouffe, 1994: 12).

No nosso entender, a revalorização conceitual e política do local em sociedades complexas como as atuais, deveria, portanto, considerar as diferenças culturais e sociais como pressupostos do reconhecimento moral, do equacionamento das tensóes entre o público e o doméstico (Arendt, op. cit.: 51), mas também da resolução das tensóes entre a igualdade e o pluralismo (Walzer, 2005: 84-85). Não basta, logo, para se entender a democracia plu- 
ralista, reconhecer os antagonismos com meras diferenças, como tem feito o liberalismo - e também J. Habermas com sua tese sobre o consenso -, mas de entender que a distinção entre o inimigo e o adversário não é algo menor na estruturação do mundo da vida. Tal distinção, explica Mouffe, permite entender que "no interior do nós que constitui a comunidade política, o opositor não deve ser considerado um inimigo cuja existência deve ser eliminada mas um adversário cuja existência é legitima” (Mouffe, 1994: 14). A partir daí, a autora valoriza a distinção entre o antagonismo (relação ao inimigo) do agonismo (relação ao adversário) que é uma categoria central na sua tese acadêmica.

Certamente, o reconhecimento do agonismo como pressuposto de organização da política coloca em cheque as teses de que o pluralismo democrático nasce ou do consenso (J. Habermas) ou do dissenso (N. Luhmann). Diversamente, o agonismo revela diretamente a presença do dom, de sistemas de prestaçóes e contraprestaçôes, que escapam a toda instrumentalização para revelar a expressividade congênita do ser humano na sua vivencia grupal, onírica e material. Urge considerar, portanto, na discussão sobre a democracia plural e sobre a formação da esfera pública democrática, as condiçóes pelas quais os atores redefinem suas hierarquias de valores, em geral incorporadas inconscientemente, para se tornarem cidadãos culturalmente visíveis e portadores de açóes solidárias valorizadoras do bem público.

Com este propósito, buscamos aprofundar neste texto o conceito de simbólica associativa para explorar seu interesse em termos de ação coletiva e esfera pública. Isto implica compreender os fundamentos morais que condicionam os desejos dos indivíduos de estarem juntos e de partilharem iniciativas comuns, como se fosse algo absolutamente natural. De fundarem experiências de dignidade na vida cotidiana, que permitem não apenas direitos objetivos mas, sobretudo, direitos subjetivos, para cada indivíduo e grupo, como acontece na modernidade ocidental (Taylor, op. cit.: 30). Tais experiências redundam em resoluçôes culturais mais complexas do dom, que deixa de se referir apenas a pactos comunitários, abrindo-se para o anonimato (Godbout em colaboração com Caillé, 1998: 81-96) como é o caso da dádiva entre estranhos e para o individualismo (Godelier, 2004: 12).

Nosso interesse é trazer uma discussão mais efetiva sobre o simbolismo, dando ênfase particular à contribuição de Marcel Mauss (2003), cuja noção de "fato social total" tem um valor heurístico particularmente pertinente para se compreender a relaçáo subjetiva entre cultura e política. Por fim, tentaremos desenvolver algumas reflexóes relativas à importância de uma cultura do dom fundada nas alianças primárias, que nos parece um desafio necessário para se entender a emancipação de novas esferas públicas híbridas e participativas, sem as quais a vida associativa é um projeto precário.

\section{O embaraço democrático}

Fóruns sociais, orçamentos participativos, conselhos municipais, assembleias e plenárias, mobilizaçóes locais de grupos de mulheres e de orientaçóes sexuais diversificadas, movimentos étnicos, nacionalistas, culturais e religiosos, tudo isso compóe o quadro que tem sido conhecido como democracia participativa nas duas últimas décadas. Acreditou-se que a institucionalização dos movimentos sociais, o crescimento do número de organizaçóes não-governamentais transnacionais, o surgimento de governos de esquerda mais sintonizados com as novas demandas sociais e culturais, e as manifestaçóes de rua nas grandes 
cidades, seriam sinais de que estaria para acontecer, brevemente, uma mudança importante nas lutas anti-globalizaçáo e na implantação de um socialismo promissor ancorado na democracia participativa.

As primeiras avaliaçóes sérias sobre o assunto ${ }^{2}$ demonstram que foram importantes os ganhos resultantes de mobilizaçóes sociais e culturais voltadas à criação de novos mecanismos de participação e de reconhecimento identitário, no âmbito do planeta, das naçôes, dos municípios e comunidades. A cada dia, surgem novas experiências que sugerem estar em curso uma grande reforma das instituiçóes sociais e culturais, com o surgimento de redes associativas que estimulam a criatividade e a solidariedade dos atores e agências no plano horizontal.

O preocupante, porém, é observar que essas reformas não parecem apontar necessariamente para o fortalecimento de um novo tipo de regime democrático, legitimado em uma ampla rede de solidariedade estendida nos planos local, nacional e planetário. Pelo contrário, ao se analisarem diferentes experiências, tidas como exemplares, percebem-se indícios preocupantes de um mal-estar crescente, revelado por sinais como a fragmentação dos direitos de cidadania, o aumento das iniquidades sociais e das distâncias entre os mais ricos e os mais pobres, a manipulação generalizada da opinião pública pelo marketing eleitoral, o desinteresse crescente dos jovens pela participação direta na vida política. Em conjunto, tais fenômenos sugerem que o princípio do igualitarismo universal próprio, a experiência republicana e a preservação do ideal de um bem comum superior à soma dos bens individuais, estariam sendo ameaçados em vez de preservados e ampliados. Se a desconstrução do universalismo é importante, por um lado, para se fazer a crítica do racionalismo iluminista, por outro, ela se torna um problema no momento em que o excesso de relativismo ameaça, como diz Mouffe, a permanência de um projeto político de realização da igualdade e da liberdade para todos (Mouffe, 1994: 31).

Ilustremos esta discussão com uma experiência concreta, a do orçamento participativo (OP) na cidade do Recife (Brasil), que vem se constituindo numa bandeira importante do governo do Partido dos Trabalhadores (PT), desde 2002. Analisando-se o quadro de distribuição de recursos, percebe-se que os grupos com mais sucesso prático na apropriação dos recursos públicos são aqueles formados por mulheres, por negros e por animadores culturais, revelando a força organizadora desses grupos nos processos decisórios locais. As pressôes exercidas por grupos e mobilizaçôes locais, sobre os gestores públicos, resultam numa distribuição assimétrica e desigual de bens coletivos entre os atores institucionais envolvidos, o que escapa, pelo menos teoricamente, ao ideal de um igualitarismo que beneficie a todos. Isso estabelece uma situação paradoxal.

Por um lado, tais pressóes são legítimas dentro de uma ótica utilitarista liberal na qual cada um, coerente com o princípio da liberdade, receberia aquilo que corresponde às finalidades perseguidas a partir do próprio interesse. Por outro, tal mecanismo gera novas desigualdades que levam a democracia, como experiência de gestáo igualitária, livre e voltada para o bem comum e público, a perder credibilidade em favor de um sistema hierárquico desigual de distribuição de renda. Conclui-se, entấo, que estas assimetrias no

2 A Revue du Mauss organizou um número especial, intitulado 'Alter-démocratie, alter-économie: chantiers de l'espérance' (2005), que contém reflexôes interessantes sobre a importância de se avançar num novo debate sobre a democracia, devido aos mecanismos da democracia representativa não bastarem para garantir os princípios de uma igualdade universalista. 
funcionamento de programas descentralizados, como o orçamento participativo, não são meros acidentes de percurso resultantes da tensão entre redistribuição e reconhecimento. Elas revelam também a presença e/ou sobrevivência de um sistema de dominaçáo voltado para a manipulação mesmo que involuntária da representação, que se camufla no discurso da participação democrática ${ }^{3}{ }^{4}$.

As experiências sugerem haver no ar uma ameaça de impasse da luta democrática, realçando problemas antigos - as dificuldades crescentes de regulação das diferenças entre os mais ricos e os mais pobres nas democracias modernas -, e revelando novos problemas como os obstáculos múltiplos à manutenção de uma política de redistribuição de bens coletivos que preserve a perspectiva do interesse público e comum -, num contexto de forte diversificação identitária.

As teorizaçôes em curso sobre as experiências de democracia participativa deixam perceber um problema teórico bem mais geral. Observa-se, assim, em escala planetária, incluindo a América Latina, a emergência de uma tendência particularista da luta pela igualdade (iguais pela similaridade identitária) que vem tomando a dianteira dos que defendem a representação universalista tradicional da igualdade (iguais pela similaridade jurídica), que vem sendo objeto de novas teorizaçóes. Alain Caillé vê os processos em curso como expressôes de uma "parcelarizaçáo" sem limites da política, ou seja, o surgimento de um movimento de multiplicação ilimitado de demandas por participação, que é preocupante por comprometer o valor da universalidade. O risco político da excessiva demanda por direitos setorializados - que não mais se pautam pelas referências da igualdade universal, mas pelos interesses grupais localizados - é de se sair da democracia para entrar num sistema parcelado, "que oscila na ilimitação pela via da exaltação do heterogêneo e pelo sacrifício das liberdades coletivas em favor da liberdade individual, que é hipostasiada e fantasmatizada" (Caillé, 2006a: 92, tradução nossa). O dilema central que se coloca no presente momento não é, então, entre mais ou menos participação e representação, porém entre a democracia participativa e a diluição das experiências democráticas, num jogo de fragmentação da memória do igualitarismo universalista.

Por outro lado, esta "parcelarização" e a descrença crescente a respeito das instituiçôes democráticas reforçam os interesses privados e especulativos, facilitando o avanço do projeto neoliberal. Este, pelo mesmo movimento que dissemina o utilitarismo mercantil e o individualismo consumista, aprofunda as tendências de desigualdade social, de ampliação das fraturas culturais e identitárias e de dissociação dos laços de solidariedade nos âmbitos da comunidade e da cidadania, permanecendo a família um refúgio afetivo-cognitivo dos indivíduos num mundo fragmentado.

${ }^{3}$ Na sua tese de doutorado sobre a cidade do Recife, Paul Cary observa que o OP desta cidade parece mais a contrapartida de uma obrigação moral dos dirigentes do Partido dos Trabalhadores que a expressão de uma confiança concreta nas capacidades das classes populares de se autogovernarem, o que, conclui ele, contribui para um certo mal-estar resultante do fato de que se estabelece uma nova separação hierárquica entre dirigentes e administrados (Cary, 2005: 227).

4 As dificuldades de emancipação da democracia participativa não sẫo apenas vivenciadas pelos países do Sul. Trata-se de um fenômeno muito mais geral ligado ao aumento das desigualdades sociais, tanto nos países ricos como pobres. François Dubet, ao analisar a situação da escola na França, por exemplo, observa que ela vem contribuindo para aumentar as desigualdades naquele país (Dubet, 2003: 45). Este tipo de problema vem se verificando de modo mais ou menos intenso em escala planetária. 
Evelina Dagnino (2004: 99) denomina de "confluência perversa” um fenômeno recente de cooptação de entidades e grupos da sociedade civil pelo Estado, servindo à adaptação do projeto neoliberal em contextos de capitalismo periférico, como o brasileiro. Ela explica que a inserção institucional de setores da sociedade civil visando uma atuação conjunta com o Estado, com a finalidade de aumentar o seu potencial participativo, tem contribuído para apagar distinçóes e divergências e gerar um vocabulário comum de procedimentos e mecanismos institucionais que enfraquecem a dimensão política da cidadania e da solidariedade (Dagnino, 2004: 108). Confluência perversa expressa, então, um processo de centralização de decisóes que desfaz os mecanismos de mediação institucionais e políticos que possibilitam a existência efetiva do direito público, em nome da necessidade de assegurar a distribuição de serviços e benefícios sociais exigidos por demandas particularizadas e utilitárias. Confluência perversa designa o deslocamento de significados, produzido pelo neoliberalismo no Brasil e em sociedades com características similares, o qual exalta a presença de uma sociedade civil ativa, não para garantir o projeto participativo mas justamente o contrário, para fragmentar a memória institucional da igualdade universalista da ação pública em favor da lógica dos ganhos e da especulação econômico-financeira.

Uma das teses que pretendemos desenvolver neste texto é, assim, de que o atual embaraço democrático tem como uma das explicaçóes centrais, no debate acadêmico, a indefinição conceitual do termo democracia participativa. Por um lado, esta indefiniçáo tem um caráter histórico: ela revela um dilema subjacente - aquele entre democracia representativa (e o poder da representação) e democracia direta (e o poder da identificação) -, devidamente lembrado por Jacques Godbout (2005). Por outro lado, tal indefinição tem um caráter semântico: a redução do termo participação à mobilização intencional e direta de grupos organizados em torno de temas culturais e sociais.

Este reducionismo do termo participação deixa de lado o fato de que a prática associativa pressupóe que os indivíduos e agentes sociais, presentes na ação, compartilhem de significados comuns ou próximos a respeito da vida comunitária ou do bem comum e público, algo já entendido há um século pelos autores pragmatistas (Cooley, 1966; Dewey, 1997). Neste texto vamos propor, então, que uma das saídas para repensarmos os impasses acerca da definição de democracia participativa é o de focalizar teoricamente, com mais intensidade, o simbolismo, de modo a que possamos entender a democracia primeiramente como originada nas experiências primárias do dia a dia, como o fizeram os pragmatistas, experiências que, lembra Chanial (2001), têm estreita correspondência com o sistema da dádiva.

Compreender a democracia participativa primeiramente como uma prática cultural e de associação, a qual se revela quando são dadas as condiçóes básicas para emergir o sentimento de pertencimento grupal, é uma forma de se priorizar o mundo da vida sobre o dos sistemas. Mas esta alternativa é a única maneira de se valorizar um olhar sobre o cotidiano que não se restrinja ao microssocial, abrindo-se ao macrossocial, como o fez Mauss com a tese do "fato social total". E este olhar sobre a realidade apenas emerge quando os indivíduos e agentes coletivos compartilham símbolos comuns no trabalho, na política e na vida cotidiana, símbolos que são por natureza dons e alianças (Caillé, 2000).

Pretendemos demonstrar que o salto teórico qualitativo em termos do conceito de democracia participativa apenas pode ser alcançado se visualizarmos a participaçáo coletiva na política como prática cultural, ou, mais precisamente, a democracia participativa como cultura do dom, da aliança e da solidariedade em torno do bem comum e, no caso das sociedades modernas, do bem público. Aqui, não é a ação intencional ou a vontade de 
poder de alguns indivíduos, mas a vivência coletiva de certos simbolismos que engendra a associação e o dom, tanto no espaço privado como no público ${ }^{5}$.

Pela consideração do dom como simbolismo, acreditamos ser possível avançar numa nova relação entre democracia e ação pública. Isto é, as possibilidades de se repensar a ação pública a partir das novas exigências de reconhecimento e de participação apresentadas pelos atores-autores da sociedade civil, devem implicar em se considerar com atenção, ao mesmo tempo e com a mesma valoração, o direito e a prática; tanto as mobilizaçóes concretas dos cidadáos em torno de símbolos compartilhados no imaginário social e político, como o imperativo da universalidade de valores e regras plurais, que se voltem para resguardar a liberdade e a igualdade de todos, como sugere com pertinência Mouffe (1994: 31).

Seguindo esta linha de raciocínio, nossa hipótese é de que a institucionalização da democracia participativa de forma mais permanente, depende do surgimento de uma cultura do dom e da associaçáo, a qual, na verdade, para sermos mais precisos, deveria ser tratada no plural, como culturas do dom. O sistema do dom, dos movimentos de doaçóes, recebimentos e retribuiçóes que estão presentes em todas as sociedades humanas já existentes, como observa Marcel Mauss no seu texto Ensaio sobre o dom: forma e razáo da troca nas sociedades arcaicas, de 1924, é o referente básico de que nos servimos neste trabalho para desenvolver nossa reflexão sobre as perspectivas de uma cultura democrática participativa de base associativa, pluralista e universalista. Açôes mais efetivas a médio e longo prazos e voltadas para a emancipação de uma democracia participativa de caráter associativo, deveriam considerar a importância do dom na prática cotidiana. Não apenas como uma experiência pontual, limitada à família ou grupos de amigos, mas como um modo efetivo de se viver generosamente e reciprocamente a si mesmo, ao outro e à comunidade.

Contudo, para clarearmos esta reflexão, devemos esclarecer, primeiramente, o que entendemos pelo termo cultura, de modo a defendermos, em seguida, o valor do dom como cultura e a democracia participativa como cultura do dom.

\section{Cultura, dom e democracia}

Nos limites do presente texto, nossa preocupação é de explorar o uso do simbolismo dentro da sociologia política e dos estudos sobre democracia, a qual pode ser resumida na seguinte questão: como podemos definir uma cultura do dom e do simbolismo, que nos auxilie no entendimento de uma democracia participativa, fundada na aliança e solidariedade, no atual contexto de fragmentação social e diversidade identitária? No nosso entendimento, os estudos maussianos nos oferecem elementos importantes para avançar nesta discussão e para sairmos dos limites da abordagem procedimentalista da política, que prendeu nossa atenção na primeira parte deste artigo.

Em primeiro lugar, é necessário dizer que, na perspectiva de Mauss, a compreensão da democracia participativa, como cultura do dom, deve considerar que as práticas culturais de base associativa surgem, necessariamente, das relações interpessoais e dos sistemas de prestações e contraprestaçóes fundados na doação, no recebimento e na retribuição de bens

\footnotetext{
${ }^{5}$ Este novo tipo de prática cultural surge paulatinamente, como já vimos, nas experiências associativas territorialmente localizadas, nos bairros e comunidades e, também, em novos espaços de significação da política, como os conselhos municipais e as mobilizaçôes políticas espontâneas de ruas.
} 
simbólicos e materiais, envolvendo comunidades, grupos e famílias. A dimensão do simbolismo é fundamental na reflexão sobre a troca em Mauss, diz Merleau-Ponty, na medida em que apenas ela permite o acesso ao outro, a compreensão do outro, sem que sacrifiquemos nossa lógica ou a lógica do outro (Merleau-Ponty, 1960: 124). Diferentemente de leituras sobre o simbolismo, que o condicionam à dimensão fonética e formal da linguagem, aquela proposta por Mauss no Ensaio sobre a dádiva (Mauss, 2003) tem, claramente, um valor prático associado à aliança entre os homens, aos seus vínculos ${ }^{6}$.

Merleau-Ponty esclarece ainda, a respeito de Mauss, em seu texto "De Mauss à Claude Lévi-Strauss", que "concebendo o social como um simbolismo, ele criou as condiçóes para se respeitar a realidade do indivíduo, aquela do social e a variedade de culturas, de modo que não permanecessem impermeáveis umas à outras" (Merleau-Ponty, 1960: 126, tradução nossa). A compreensão do social como simbolismo permite superar os modelos teóricos dicotômicos e lineares, para se entender as partes em interação a partir de uma totalidade mítica invisível, de uma espécie de síntese primeira que funciona como cimento afetivo e significativo dos múltiplos eventos que permeiam o contexto e que se articulam, apesar de suas variedades. ${ }^{7}$

Em segundo lugar, podemos propor que o entendimento da democracia participativa, como cultura do dom, se explica pelo fato de que os ideais morais de bem comum e público, de igualdade e de justiça social, não podem ser construídos apenas pelas racionalidades dos atores sociais consideradas como objetos separados. É fundamental entender-se que a própria idéia de participação coletiva tem que ser experimentada primeiramente como um simbolismo, como um imaginário instituinte coletivo, antes de aparecer como um vivido particular qualquer. Os atores se tornam autores na medida em que partilham, voluntária ou involuntariamente, certos símbolos, representaçôes e crenças.

Ora, se o símbolo é o próprio dom e se reveste da forma de um sinalizador de alianças, ele é a condição necessária para que a coletividade experimente sentimentos e emoçóes comuns a respeito da vida e da morte, da liberdade e da obrigaçáo, do interesse e do desinteresse. Ou seja, se os dons simbolizam a aliança (Caillé, 2000: 203-206), o sentimento da participação democrática não pode resultar de nenhuma decisão calculada de indivíduo ou grupo isoladamente, mas de uma vivência comum do simbolismo. Tal compreensão da realidade humana como um sistema simbólico nos permite falar de um paradigma do dom, forma de saber e de ação, no interior da qual se forjam as alianças e o que estamos denominando de cultura do dom.

Nossa hipótese é de que uma cultura democrática participativa inédita deveria ser o desdobramento dessas experiências originárias da dádiva, ou seja, das tendências dos indivíduos

6 Isso diferencia, desde já, uma definição operacional de cultura fundada numa sociologia do ator, ou do sujeito, por um lado, de uma definição de cultura fundada na sociologia do vínculo, sobre a qual se apoiam os estudos sobre o dom, por outro. Nesta sociologia do vínculo o sujeito existe não como projeto cognitivo de indivíduos ou grupos, mas como resultado das modalidades de circulação coletiva de prestações e contraprestações nem sempre objetivadas, isto é, muitas vezes inconscientes, envolvendo a totalidade dos membros da comunidade, mesmo que frequentemente tenha ressonância diferenciada sobre os mesmos.

A noção de "hau" à qual se refere Mauss no Ensaio, quando busca descrever o espírito das coisas dadas em sociedades tradicionais estudadas, tem este valor de síntese organizativa. Mas é um erro, lembra Caillé (2000: 216), reduzir esta totalidade organizativa a leis estruturalistas de trocas, como fez Lévi-Strauss, o que impede se compreender que as funçôes simbólicas organizativas variam de cultura para cultura e como elas são refeitas em sociedades complexas como as atuais para dar nascimento a novas estruturas de significação histórico-cultural. 
e grupos se associarem de algum modo em torno de funçôes simbólicas que dão sentido à vida comunitária e associativa. Tais funçôes simbólicas são flexíveis e dependem dos contextos históricos e culturais particulares, não se reportando, por conseguinte, apenas ao mundo do trabalho ou da ação política organizada, mas ao conjunto de atividades presentes no dia-a-dia, como jogos, festas e gentilezas ${ }^{8}$. O diferencial oferecido pela cultura da dádiva para o entendimento das sociedades complexas e contemporâneas, é o de que o sistema de prestaçóes coletivas tende a ultrapassar as fronteiras do imaginário comunitário local tradicional, desenraizando os indivíduos, favorecendo novas formas de relação fundadas no anonimato (Godbout e Caillé, 1992), e incorporando esses indivíduos em esferas políticas que se translocalizam e se transnacionalizam.

O espaço tradicional da cultura do dom tinha um caráter mais propriamente obrigatório, dado pelo modo como o fato religioso condicionava a difusão do simbolismo nas festas, rituais e magias. No contexto de sociedades complexas, todavia, os membros da sociedade são convidados a definirem seus próprios sistemas de troca (Merleau-Ponty, op . cit.: 141), o que amplia grandemente o valor da liberdade individual. A cultura do dom contribui, na contemporaneidade, para refazer as obrigaçóes coletivas a partir da valorização de uma experiência de libertação do imaginário social pela individualização (Godelier, 2004) e surgimento de um self expressivo complexo (Taylor, 2005). Neste novo contexto, o simbolismo se revela mais ágil na função de significar novos sentimentos e motivaçóes coletivas voltadas para a associação. Todavia, os novos padróes de significação que os grupos emergentes criam, tanto podem apontar na direção de uma cultura de solidariedade ampla, como os movimentos pela paz ou pela preservação do meio ambiente, como podem, no sentido contrário, apontar para açóes de violência aberta contra os padróes culturais tradicionais. O primeiro desses padrôes, podemos representar, metaforicamente, pela imagem de uma pomba branca, o segundo, pela de um revólver.

A cultura do dom como base da democracia participativa deve implicar, por conseguinte, a decisão política de criação de significados coletivos que permitam articular o movimento de diversificação e de libertação de movimentos gerados pelos choques incessantes de culturas em sociedades complexas. Deve estimular a interiorização de regras morais e valores emocionais que favoreçam a solidariedade grupal e a prática da negociação discursiva e afetiva?. $\mathrm{O}$ vínculo associativo não se gera nem por baixo - a partir da perspectiva de indivíduos separados -, nem por cima - a partir da perspectiva de uma totalidade social separada -, mas a partir do seu meio, "horizontalmente, em função do conjunto de inter-relaçôes que ligam os indivíduos e os transformam em atores propriamente sociais” (Caillé, 2000: 19).

$\mathrm{Na}$ ótica de uma cultura do dom o fundamental é verificar que iniciativas políticas, jurídicas e institucionais devem ser forjadas para surgir uma democracia participativa e associativa autêntica, para nascer uma aliança que possa canalizar - sem se fragmentar - as tensôes horizontais e verticais - culturais, históricas, religiosas e morais -, geradas pelas mo-

\footnotetext{
${ }^{8}$ Esta ideia da sociedade como fato social total é o grande trunfo da contribuição de Mauss. Nele, a cultura do dom deve ser compreendida como representaçóes coletivas intrinsecamente simbólicas que se apresentam como fato social total. Nelas se incluem nossas representaçôes atuais de democracia participativa.

9 O paradigma do dom é o sistema de conhecimento mais amplo que envolve a cultura do dom e que permite compreender a realidade social de modo relacional, incluindo, pela aliança, as dimensóes macro e micro, subjetivas e objetivas e, a partir da simbólica da associaçáo, o surgimento de experiências voltadas para o bem comum, para o público.
} 
bilizaçôes dos indivíduos e grupos sociais no calor do choque cultural. O desafio, aqui, é o de se conceber uma idéia de cultura democrática de base associativa que assegure no plano simbólico a criação de um sistema normativo, moral, jurídico e institucional de caráter coletivo, universal e obrigatório, mas aberto ao mesmo tempo à diversidade, à singularidade e à liberdade. Isto é, que estabeleça uma prática institucional e política, plural e dialógica, onde o interesse deve ser mediado pelo desprendimento, onde o bem individual deve se submeter ao bem comum.

As disputas interpessoais geradas no plano das experiências diretas e locais, nos bairros, nas comunidades, nas assembléias e nos fóruns, não são casuais. Elas apontam para a existência de um conjunto de novas significaçôes que informam as práticas discursivas - as rivalidades, as celebrações, as solidariedades. Como também indicam novas modalidades de resistência geradas a partir de sentimentos de exclusão, de não reconhecimento e de abandono que provocam o surgimento de simbólicas associativas de base corporativa e particular. A partir de certo momento tais práticas podem se tornar mesmo anti-democráticas, comprometendo a manutençấo dos valores de uma cidadania equitativa e universal. Independentemente dos significados morais que adquirem as novas representaçóes profanas e sagradas da vida política, o fato é que elas são necessariamente reguladas por dispositivos - memórias, crenças, valores que favorecem o surgimento de novos lugares de enunciação e exercício do poder, regidos pelas diversidades identitárias e culturais. As novas narrativas simbólicas contribuem, tanto para promover diálogos diferenciados e legitimados pelo respeito à diferença e pelo ideal de preservação da universalidade como, no sentido contrário, para estabelecer padróes individualistas, particulares, que comprometem as bases da democracia participativa. Esta segunda tendência vem se espalhando no momento presente, mas nada indica que ela tenda a comprometer estruturalmente a memória construída sobre democracia e participação.

Em outros termos, propomos o entendimento da democracia participativa como experiência coletiva pulsante, isto é, como uma prática cultural e associativa de valor público e com potencial deliberativo, constituindo um salto teórico inestimável para superar o dilema atual entre democracia representativa e democracia direta, para ultrapassar o abismo atual entre ação por representação e ação direta por mobilização cívica.

Enfim, o projeto neoliberal não pode sustentar sua validade quando o enfocamos a partir de uma crítica cultural que permita demonstrar que a identificaçáo do fenômeno da cultura ao consumismo utilitário é um equívoco teórico, que esconde o fato de que os interesses de satisfação imediata, como o do consumo, não são naturais, mas instaurados simbolicamente. Como diz Sahlins "as atividades práticas possuem sempre um valor simbólico e os efeitos materiais, inclusive os da política, sempre se referem a um significado e a uma localização cultural" (Sahlins, 2003: 205-206). Este é o contexto em que aprofundaremos a compreensão da importância da cultura do dom para o surgimento de novas esferas híbridas, públicas e participativas.

\section{A cultura do dom e o surgimento de uma nova esfera pública participativa}

É importante articularmos esta discussão sobre uma cultura democrática e participativa fundada no dom com a instauração de políticas públicas que favoreçam o surgimento de experiências coletivas voltadas para a solidariedade: na política, na economia, nas práticas culturais e sociais. Ou seja, um novo fato moral associativo que contribua para mobilizar 
as vontades e desejos múltiplos, trazendo à tona as diferenças e singularidades, mas estimulando a negociação, a aliança e a associação, favorecendo, como propuseram os filósofos pragmatistas norte-americanos John Dewey (1997) e Charles Cooley (1966), a opinião pública e o espaço público.

Mas o novo fato associativo não pode prosperar com sucesso caso náo entendamos que a liberdade individual na contemporaneidade tem um impacto subversivo sobre o simbolismo. Merleau-Ponty compreendeu com clareza este fenômeno de estilhaçamento das estruturas simbólicas tradicionais nas sociedades complexas contemporâneas. Tal fenômeno é aquele em que os indivíduos são levados a definirem seus sistemas simbólicos a partir de suas próprias motivaçóes e experiências. Diz ele que "esta subversão significa ganhos imensos, possibilidades inteiramente novas, como, por outro lado, perdas cujo valor precisam ser mensuradas, riscos que começamos a constatar. A troca, a função simbólica, perdem sua rigidez, mas também sua beleza hierática; à mitologia e ao ritual substituem a razão e o método, mas igualmente um uso profano da vida, acompanhado, aliás, de pequenos mitos compensatórios sem profundidade" (Merleau-Ponty, op. cit.: 141).

As novas formas societais - interpessoais, intergrupais ou intercomunitárias - fundadas nas lutas pelo reconhecimento, pela inclusão, pelo respeito e pelas novas posiçóes identitárias, constituem a trama central das tentativas de culturas democráticas participativas autênticas, que resultam dessas novas estruturas simbólicas. Mas, para que estas culturas particulares se generalizem, servindo de base para modelos organizacionais mais amplos para culturas gerais - e para um novo sistema de direito associativo de base comunitária ampliada, é necessário açóes públicas que valorizem as simbólicas associativas que funcionam como cimento afetivo daquelas formas societais. O processo de criação cultural de uma nova forma de fazer política, a partir das sociabilidades primárias, revela as tramas vividas pelos sujeitos sociais no bojo de choques culturais cruzados, de uma parte, entre o tradicional e o moderno, de outra, entre o nacional e o global. A inovação cultural contemporânea manifesta, por sua vez, novas modalidades de trocas, de dádivas positivas e negativas, que são recriadas e recicladas pelos indivíduos a partir das rupturas de antigas crenças e valores e do surgimento de novas modalidades de ação.

Certamente, o clima sócio-cultural é efervescente e marcado por conflitos, rivalidades e generosidades, dentro de diferentes estruturas de poder que escapam ao controle de quaisquer poderes centralizados, como é o caso do Estado. Isto desperta uma tensão inevitável entre ação direta e ação indireta, entre democracia primária e democracia secundária, provocando deslocamentos de sentidos e surgimento de novas significaçóes coletivas que se expressam em normas, valores, crenças e regras sociais que são traduzidas nos espaços entre o indivíduo e o grupo. Por conseguinte, as perspectivas de surgimento de uma cultura democrática participativa autêntica, válida no plano macrossociológico e não apenas nos níveis microssociológicos, passam a depender das formas de regulação que sejam capazes de dissolver as tensóes diversas - entre propósitos individuais e coletivos, entre interesse e desprendimento, entre liberdade e obrigação.

A cultura democrática participativa, plural e pública - criada pela vivência coletiva do dom e do simbolismo em espaços de poder nos quais os interesses grupais, individuais e setoriais, são transformados em favor de uma nova prática de bem comum -, deve responder à questão que já se colocava Schopenhauer no século XIX. Tal questão era a de saber sob que condiçôes o bem-estar ou o mal-estar do outro move minha própria vontade, como se fosse meu próprio bem. E ele respondia que isto somente ocorre por meio de que o outro se 
torne, de tal modo, o fim último de minha vontade, como eu próprio o sou, que eu queira imediatamente seu bem-estar e náo queira seu mal-estar, tão diretamente como se fosse o meu. "Isto, porém, pressupóe necessariamente que eu sofra com seu mal-estar, sinta seu mal como se fora o meu e, por isso, queira seu bem como se fora o meu próprio. Isto, porém, exige que eu me identifique com ele, que aquela diferença total entre mim e o outro, sobre a qual repousa justamente meu egoísmo, seja suprimida pelo menos num certo grau." (Schopenhauer, 2001: 135-136).

Ou seja, este tipo de bem moral e simbólico, na perspectiva da cultura democrática fundada na aliança, não é o resultado dos interesses materiais e privados egoístas. Diferentemente, o bem público, na perspectiva de uma cultura democrática participativa fundada no dom, deve constituir um novo código de referências normativas e axiológicas não redutível aos interesses privados ${ }^{10}$, um código que supera o egoísmo individual para instaurar uma experiência de identificação com o outro, que Schopenhauer (2001: 136) sintetiza pela expressão compaixão.

As experiências atuais de democracia participativa - como são os casos dos conselhos municipais - apontam teoricamente para este salto na instituição democrática, embora, na prática, ainda tenham um longo caminho a percorrer antes de aparecer como uma realidade efetiva. Neste sentido, é conveniente para a expansão da democracia participativa que a ação pública leve em conta o valor do simbólico para a materialização da prática associativa e solidária. Certos símbolos, como a bola e o time de futebol, as cartas de baralho ou o jogo de dominó, que aparentemente são figuras banais e de pouco interesse para a política e para a ação pública, carregam em si forte componente associativo. Infelizmente, tais figuras são, em geral, menosprezadas pelos planejadores e gestores públicos que pensam - o que é uma visão limitada da política - que a conscientização do espírito de cidadania depende apenas de estratégias de convencimento e de manipulação, desconhecendo a importância do simbolismo, em geral, para promover solidariedades e adesôes a açóes de caráter público.

Apenas uma cultura democrática apoiada no simbolismo generalizado e no "fato social total" pode explicar o aparecimento de esferas públicas híbridas que articulem as práticas primárias e as secundárias, o "mundo da vida", e os sistemas formais, como o Estado. Nessas novas esferas híbridas, as vontades e açóes particulares de cidadãos e movimentos associativos, de uma parte (lado do social), e de gestores e políticos, de outra parte (lado do institucional), devem se conjugar e se sacrificar em favor do bem comum, que apenas se define a partir da idéia de participação pública. Pensando em termos das complexas sociedades contemporâneas, podemos propor que tais esferas públicas híbridas, inspiradas na idéia de uma cultura democrática, participativa, pública e eminentemente política, fundada na circularidade de dádivas, devem ser capazes de suportar pressóes diversas e muitas vezes contraditórias. ${ }^{11}$

${ }^{10}$ Este novo tipo de cultura democrática vem sendo estimulada em experiências de inspiração associativa, como os conselhos municipais. Para alguns estudiosos dos fatos urbanos, como Orlando dos Santos Júnior, Luis César de Queiroz Ribeiro e Sérgio de Azevedo (2004: 25), tanto pela força da sua difusão no País como pelas diferenças com as experiências anteriores de participação, "os conselhos municipais representam uma importante inovaçâo institucional na gestão das políticas sociais".

11 Aqui, nos referimos às pressōes verticais, resultantes do poder institucionalizado, e pressões horizontais, derivadas dos movimentos sociais e das reivindicaçóes de base, pois "a articulação social da diferença, da perspectiva da minoria, é uma negociaçáo complexa, em andamento, que procura conferir autoridade aos hibridismos culturais que emergem em momentos de transformação histórica” (Bhabha, 2003: 21). 
Atualmente, as tentativas de criação de esferas deste porte, como os Conselhos $\mathrm{Mu}$ nicipais ou os Orçamentos Participativos, ainda têm limites claros, tanto em termos de assegurar efetiva participação (Cary, 2005), como de se constituir em instância deliberativa e não apenas consultiva. ${ }^{12}$ Todavia, constituem, sem dúvida, um bom ponto de partida para se avançar nesta via de renovação da luta democrática. Afinal, a questão não é apenas de criar novas modalidades de governo democrático, mas de reformar a governabilidade e de ampliar as bases de sustentação do jogo democrático mediante uma nova compreensão sócio-antropológica do mesmo, para que ele responda mais efetivamente às novas demandas de participação e aos novos desafios de gestão pública.

Tal esfera deve ser também suficientemente flexível para lidar com novas modalidades associativas e experiências de alianças, nascidas fora dos partidos e sindicatos tradicionais e que tomam frequentemente a forma de redes sociais (Fontes e Martins, 2006; Aguiton, 2006), de movimentos de base (Matos, 2006) e de atividades lúdicas e artísticas variadas, abrindo-se para a diversidade e a singularidade. Isto significa tanto repensar o controle social, que tradicionalmente era feito de cima para baixo, denotando o viés autoritário das políticas públicas no século passado (Rodger, 1996), como liberar novas formas de proteção social fundadas numa cultura da solidariedade, plural, diversificada e singularizada. Por um lado, esta esfera pública híbrida deve ser o lócus privilegiado para administrar as trocas de informaçôes entre Estado e Sociedade Civil e definir os critérios básicos para a redistribuição de bens, riquezas, e direitos setoriais locais ${ }^{13}$. Mas, por outro, deve também ser capaz de integrar - sem cooptar - a luta pelo reconhecimento (Honneth, 2003) que tanto motiva as mobilizaçóes sociais e culturais, com vistas à formulação de políticas mais justas. Pois "a justiça hoje", lembra por sua vez N. Fraser, "requer ao mesmo tempo a redistribuição e o reconhecimento" (Fraser, 2005: 152, tradução nossa).

\section{Conclusão}

Uma esfera pública híbrida, participativa e deliberativa, baseada na cultura do dom, deve funcionar como território simbólico para uma nova modalidade coletiva de gestáo do poder social. Ela pode e deve comportar várias dimensóes: o saber especializado e o saber comum, a ciência e a arte, o Estado e a Sociedade, a vida no trabalho e o lazer, a seriedade e a brincadeira. Deve absorver, sem se fragmentar, tensôes culturais e políticas contrárias em torno da igualdade libertária ou do que Amartia Sen designa de uma "liberdade-igual", pela qual "a crença de que uma liberdade é importante não pode estar em conflito com a visão de que é importante que os ordenamentos institucionais sejam dispostos para promover a

12 Os Conselhos de Saúde foram criados oficialmente pela Lei no 142/90, que os definiu como espaços vitais para o exercício do controle social do Sistema Único de Saúde (SUS). As atribuições legais e políticas dos Conselhos são: a) atuar na formulação de estratégias de operacionalização da política de saúde; e b) atuar no controle social da execução da política de saúde. Ao longo dos anos tais Conselhos vêm sendo estruturados em vários estados e municípios. As experiências de implantaçáo de unidades de saúde, assim como o debate nas grandes conferências de saúde, permitiram uma compreensão crescente sobre a importância da capacitação dos conselheiros como uma das medidas para aperfeiçoar este instrumento de gestão participativa, o que foi consolidado no documento Diretrizes nacionais para a capacitação dos conselheiros de saúde, publicado em 1999.

13 O Estado do bem-estar no século XX, como lembra P. Rosanvallon (1981), exerceu este papel, mas referindo-se a uma categoria de cidadania limitada ao trabalho, à cotização e à securitização, o que não é mais o caso hoje. 
igualdade de liberdades que as pessoas têm" (Sen, 2001: 53). Não há como se pensar, pois, uma cultura da dádiva capaz de suportar uma democracia participativa universalista sem que se superem as tensóes entre representação e identificação. E tal superação apenas se faz pela consideraçáo de todo o simbolismo existente nas memórias e representaçóes coletivas, informais e organizacionais.

Há, evidentemente, dificuldades teóricas inúmeras a serem resolvidas para a compreensão desta nova cultura democrática participativa fundada no dom, no simbolismo e na associaçáo. O fundamental é entender que a cultura do dom náo resulta de meras estratégias ou tentativas calculadas de se controlar a açáo de outrem, mas justamente do contrário: da superação das barreiras entre eu, mim e o outro, tema que foi teorizado de modo exemplar por George Mead (1967). Esta superação é a condição para que o dom apareça como política de reconhecimento cultural e associativa, num mundo aberto em permanência à novas formulaçóes simbólicas que produzem tensóes na totalidade social a partir das redes associativas diferenciadas e plurais e da individualizaçáo incessante.

Tal observação é particularmente pertinente em sociedades como aquelas do Sul, em que a precariedade do trabalho assalariado não deve ser traduzida como um impasse histórico que condenaria tais sociedades ao "subdesenvolvimento". Ao contrário, pelo entendimento da sociedade como fato social total, podemos verificar existir uma diversidade de estruturas simbólicas à disposição para se pensar a autonomia sócio-histórica. Mas o modo como os simbolismos são traduzidos e apropriados por diferentes sociedades depende, basicamente, do fazer político, da capacidade de se organizar novas formas associativas, e de se fundar uma cultura do dom e da associação que se enraíze nos saberes, nos desejos e nos sonhos dos cidadãos. Pensando de forma abstrata tal desafio parece uma utopia, mas, ao nos debruçarmos sobre as condiçôes concretas de produção da cultura, da sociedade e da política, podemos constatar haver experiências em desenvolvimento que são muito originais e promissoras. Sobre elas podemos começar realisticamente a pensar os fundamentos da cultura democrática participativa e associativa de valor universal, cujos fundamentos procuramos delinear no presente trabalho.

Pensamos, enfim, que o trabalho de mapeamento de tais experiências assim como os esforços de articulação e de divulgação das mesmas, nos moldes como vem sendo realizado, por exemplo, por Boaventura de Sousa Santos, é decisiva para se organizar novos espaços de solidariedade e de participação no plano transnacional ao mesmo tempo em que reforça as lutas locais de ampliaçáo dos espaços de reconhecimento e de participação. 


\section{Referências Bibliográficas}

AGUITON, Christophe - «Crise et renouveau de la démocratie en période de mondialisation». In CAILLÉ, Alain (Dir.) Quelle démocratie voulons-nous ? Pièces pour un débat. Paris: La Découverte, 2006.

ARENDT, Hannah - A condição humana. Rio de Janeiro: Forense Universitária, 2003.

BHABHA, Homi - O local da cultura. Belo Horizonte: Editora da Universidade Federal de Minas Gerais, 2003.

CAILLÉ, Alain (2000) Anthropologie du don : le tiers paradigme. Paris: Desclée de Brouwer.

CAILLÉ, Alain - «Un totalitarisme démocratique ? Non, le parcellitarisme». In CAILLÉ, Alain (Dir.) Quelle démocratie voulons-nous? Pièces pour un débat. Paris: La Découverte, 2006a.

CAILLÉ, Alain - «Introduction». In CAILLÉ, Alain (Dir.) Quelle démocratie voulons-nous? Pièces pour un débat. Paris: La Découverte, 2006b.

CARY, Paul - «Qui participe à quoi?» Revue du MAUSS semestrielle: Alter-démocratie, alter-économie. Chantiers de l'espérance, no 26, 2005, pp. 211-230.

CASSIRER, Ernst - A filosofia das formas simbólicas: II - o pensamento mítico, São Paulo: Martins Fontes, 2004.

CHANIAL, Philippe - Justice, don et association: la delicate essence de la democracie. Paris: La Découverte, 2001.

COOLEY, Charles N. - Social process. Carbondale: Southern Illinois University Press, 1966.

DAGNINO, Evelina - «Sociedade civil, participação e cidadania: de que estamos falando?». In MATO, Daniel (Coord.) Políticas de ciudadanía y sociedad civil en tiempos de globalización. Caracas: Universidad Central de Venezuela, 2004.

DEWEY, John - The public and its problem. Athens: Ohio University Press, 1997.

DUBET, François - As desigualdades multiplicadas. Ijuí: Editora Unijuí, 2003.

FONTES, Breno; MARTINS, Paulo Henrique (Orgs.) - Redes, práticas associativas e gestão pública. Recife: Editora da Universidade Federal de Pernambuco, 2006.

FRASER, Nancy - Qu'est-ce que c'est la justice sociale? Paris: La Découverte, 2005.

GODBOUT, Jacques em colaboração com CAILLÉ, Alain - L'esprit du don. Paris: La Découverte, 1992.

GODBOUT, Jacques em colaboração com CAILLÉ, A. - O espírito da dádiva, Rio de Janeiro: FGV, 1998.

GODBOUT, Jacques - «Pas de représentation sans représentativité». Revue du MAUSS semestrielle: Alter-démocratie, alter-économie. Chantiers de l'espérance, n. 26, 2005, pp. 90-104.

GODELIER, Maurice - Métamorphoses de la parenté. Paris: Fayard, 2004.

HABERMAS, Jurgen - Direito e democracia: entre facticidade e validade. Rio de Janeiro: Tempo Brasileiro, 2003.

HONNETH, Axel - Luta por reconhecimento, São Paulo: Editora 34, 2003.

JONAS, Hans (1997) Le principe responsabilité: une éthique pour la civilisation technologique, Paris: Les Editions du CERF.

LÉVI-STRAUSS, Claude - As estruturas elementares do parentesco, 3a Edição, Petrópolis: Vozes, 2003.

MATOS, Aécio - «Participação e democracia». In FONTES, Breno; MARTINS, Paulo Henrique (Orgs.) Redes, práticas associativas e gestão pública. Recife: Editora da UFPE, 2006.

MAUSS, Marcel - Sociologia e antropologia, São Paulo: Cosac \& Naify, 2003.

MOUFFE, Chantal - Le politique et ses enjeux: pour une democratie plurielle, Paris: La Découverte/MAUSS, 1994.

MEAD, George H. - Mind, self and society, Chicago: The University of Chicago Press, 1967.

MERLEAU-PONTY, Maurice - «De Mauss à Claude Lévi-Strauss». In Idem, Éloge de la philosophie, Paris: Gallimard, 1960.

NEVES, Marcelo - «Do consenso ao dissenso: o Estado democrático de direito a partir e além de Habermas» In Sousa, J. (org.) Democracia hoje: novos desafios para a teoria democrática contemporânea, Brasília: Editora da Universidade Nacional de Brasília, 2001.

RODGER, John - Family life \& social control: a sociological perspective. London: Macmillan, 1996.

ROSANVALLON, Pierre - La crise de l'Etat-providence, Paris: Seuil, 1981.

ROSANVALLON, Pierre - La nouvelle question sociale: repenser l'Etat-providence, Paris: Seuil, 1995.

SAHLINS, Marshall - Cultura e razão prática. Rio de Janeiro: Jorge Zahar, 2003.

SANTOS JÚNIOR, Orlando Alves dos; RIBEIRO, Luiz Cesar de Queiroz; AZEVEDO, Sérgio de - «Democracia e gestão local: a experiência dos conselhos municipais no Brasil». In Idem (Orgs.) Governança democrática e poder local: a experiência dos conselhos municipais no Brasil. Rio de Janeiro: Revan/ Fase, 2004.

SCHOPENHAUER, Arthur - Sobre o fundamento da moral, São Paulo: Martins Fontes, 2001.

SEN, Amartya - Desigualdade reexaminada. Rio de Janeiro: Record, 2001

TAYLOR, Charles - As fontes do self: a construção da identidade moderna, São Paulo: Ediçóes Loyola, 2005.

WALZER, Michael - Politics and passion: toward a more egalitarian liberalism, New Haven \& London: Yale University Press, 2005. 